OPEN ACCESS

Edited by:

Marco Scarpa

University Hospital of Padua, Italy

Reviewed by:

Antonio Simone Laganà,

University of Insubria, Italy

Massimo lafrate,

University Hospital of Padua, Italy

${ }^{*}$ Correspondence:

Anguo Wang

wanganguo2019@163.com

${ }^{\dagger}$ These authors have contributed equally to this work

Specialty section:

This article was submitted to

Surgical Oncology,

a section of the journal

Frontiers in Oncology

Received: 16 July 2020 Accepted: 24 September 2020

Published: 29 October 2020

Citation:

You C, Du Y, Wang H, Peng L, Wei T,

Zhang $X$, Li $X$ and Wang A (2020)

Laparoscopic Versus Open Partial

Nephrectomy: A Systemic

Review and Meta-Analysis of

Surgical, Oncological, and

Functional Outcomes.

Front. Oncol. 10:583979.

doi: 10.3389/fonc.2020.583979

\section{Laparoscopic Versus Open Partial Nephrectomy: A Systemic Review and Meta-Analysis of Surgical, Oncological, and Functional Outcomes}

\author{
Chengyu You ${ }^{\dagger}$, Yuelin $\mathrm{Du}^{\dagger}$, Hui Wang, Lei Peng, Tangqiang Wei, Xiaojun Zhang, \\ Xianhui Li and Anguo Wang*
}

Department of Urology, Nanchong Central Hospital, The Second Clinical College, North Sichuan Medical College (University), Nanchong, China

Purpose: To summarize and analyze the current evidence about surgical, oncological, and functional outcomes between laparoscopic partial nephrectomy (LPN) and open partial nephrectomy (OPN).

Materials and Methods: Through a systematical search of multiple scientific databases in March 2020, we performed a systematic review and cumulative meta-analysis. Meanwhile, we assessed the quality of the relevant evidence according to the framework in the Cochrane Handbook for Systematic Reviews of Interventions.

Results: A total of 26 studies with 8095 patients were included. There was no statistical difference between the LPN and OPN in the terms of operation time $(p=0.13)$, intraoperative complications ( $p=0.94)$, recurrence $(p=0.56)$, cancer-specific survival $(p=0.72)$, disease-free survival $(p=0.72)$, and variations of estimated glomerular filtration rate $(p=0.31)$. The LPN group had significantly less estimated blood loss $(P<0.00001)$, lower blood transfusion $(p=0.04)$, shorter length of hospital stay $(p<0.00001)$, lower total $(p=0.03)$ and postoperative complications ( $p=0.02)$, higher positive surgical margin $(p=0.005)$, higher overall survival $(p<0.00001)$, and less increased serum creatinine $(p=0.002)$. The subgroup analysis showed that no clinically meaningful differences were found for T1a tumors in terms of operation time $(\mathrm{p}=0.11)$ and positive surgical margin $(\mathrm{p}=0.23)$. In addition, the subgroup analysis also suggested that less estimated blood loss $(p<0.0001)$ and shorter length of hospital stay $(\mathrm{p}<0.00001)$ were associated with the LPN group for T1a tumors.

Conclusions: This meta-analysis revealed that the LPN is a feasible and safe alternative to the OPN with comparable surgical, oncologic, and functional outcomes. However, the results should be applied prudently in the clinic because of the low quality of evidence. Further quality studies are needed to evaluate the effectiveness LPN and its postoperative quality of life compared with OPN.

Keywords: kidney neoplasm, laparoscopy, nephrectomy, surgical procedures, treatment outcomes 


\section{INTRODUCTION}

For T1 $(\leq 7 \mathrm{~cm})$ renal masses, partial nephrectomy $(\mathrm{PN})$ is the preferred surgical treatment, which is suggested by guidelines (13). On the one hand, PN is similar to radical nephrectomy in oncological safety $(4,5)$. On the other hand, PN protects kidney function better and reduces the incidence of cardiovascular diseases $(4,6)$. Although laparoscopic PN (LPN) is an enormous technical challenge and has a steep learning curve, it is obviously becoming a feasible alternative to open PN (OPN) with less blood loss, fewer complications, and comparable oncologic and functional outcomes (7-11).

With the development of laparoscopic techniques, the robotic technique has been frequently reported $(12,13)$. However, the robotic technology has not been fully popularized because of the limitations of economics or cognitions. Recently, hybrid transvaginal note nephrectomy also brought about widespread attention due to the superiority of sexual function, especially in the female population, but it needs further verification $(14,15)$. Therefore, the LPN is the first choice for primarily experienced centers because of better cost-efficacy (16).

There is always a lack of systemic evidence for LPN versus OPN even though the numbers of studies on it have increased recently. It is high time to perform a meta-analysis of outcomes for LPN versus OPN even though there are no randomized studies. Consequently, we conducted a systemic review and meta-analysis for LPN versus OPN, including surgical, oncological, and functional outcomes.

\section{METHODS}

The protocol of this review was registered prospectively (CRD42020178120) in the PROSPERO database (University of York, York, United Kingdom). The study was performed according to the preferred reporting items for systematic reviews and meta-analysis (PRISMA) statement (17).

\section{Literature Search and Study Selection}

In April 2020, a comprehensively systematic literature search was conducted by using PubMed, the Cochrane Library, and Embase databases. The different search strategies were used for corresponding research engines, respectively. Search terms combined participant terms (kidney or renal neoplasm, kidney or renal cancer, kidney or renal carcinoma, kidney or renal tumor), intervention terms (partial nephrectomy or nephronsparing surgery), and comparison terms (laparoscopic or laparoscopy, open). What is more, additional records were identified through manually searching references in the selected manuscripts or in the review articles. Literature searching imposed restrictions including being published in the English language and published from 2000 to 2020.

The studies focused on patients with kidney cancer and comparing surgical, oncological and functional outcomes between LPN and OPN were included. The studies involving patients with kidney tumor $>7 \mathrm{~cm}$ were excluded to minimize the differences caused by the size of tumor. To eliminate discrepancies from the surgical approach, only the patients who underwent LPN were included. The studies that reported hand-assisted or robot-assisted laparoscopic technology were excluded. Meanwhile, letters, cases, reviews, conference abstracts, and studies that are irrelevant to the theme or lack complete data were excluded in order to enhance the feasibility and quality of the conclusions.

All included studies were assessed according to the methodological index for nonrandomized studies (MINORS) with a total of 24 points, which involves 12 items (18). In addition, the level of evidence of each study was assessed by the Oxford Centre of Evidence Based Medicine criteria (19). In addition, the risk of bias of each study included was independently assessed using the Risk of Bias in NonRandomized Studies of Interventions tool (ROBINS-I) for comparative studies (20).

In addition, a subgroup analysis was performed in the patients with clinical Tla stage tumor to compare the two surgical techniques simply because the size of tumor is associated with surgical outcomes.

\section{Data Extraction}

All outcomes of interest were collected in a piloted form, including the characteristics of selected studies, surgical, oncological, and functional outcomes. For the characteristics, the following items were included: author's name, study design, number of patients, mean age, gender ratio, tumor location, tumor pathology, tumor size, and follow-up duration. The surgical outcomes included operation time, estimated blood loss (EBL), blood transfusion, length of hospital stay (LOS), and complications (total, intraoperative, and postoperative). The oncological outcomes contained positive surgical margin (PSM); recurrence; and survival results, including overall survival (OS), cancer-specific survival (CSS), and disease-free survival (DFS). The items of variations of estimated glomerular filtration rate (eGFR) and serum creatinine $(\mathrm{sCr})$ were recorded for the functional outcomes. For survival data, we excavated data from Kaplan-Meier curve using Engauge Digitizer version 4.1 (http:// digitizer.sourceforge.net/) for the studies without direct survival data.

The above two steps (literature search and data extraction) were completed by three of us (CY, YD, HW) independently. All disagreements were resolved by a senior author (AW) after public discussion.

\section{Data Analysis}

The Review Manager software (RevMan) version 5.3 (the Cochrane Collaboration) was used for statistical analysis in our study. The mean difference (MD) and odds ratio (OR) were calculated for continuous and dichotomous variables, respectively, with $95 \%$ confidence intervals (CIs). In addition, the hazard radio (HR) with 95\% CIs was used for CSS and DFS. We used special statistical methods for studies that presented merely continuous data as median and range values (21). The heterogeneity between studies was assessed by using the chisquared and I- squared test. Random-effects models were used 
for cumulative analyses, which had high heterogeneity $\left(\mathrm{I}^{2}>90 \%\right)$. Otherwise, fixed-effects models were used for analyses. Finally, $P$ values of $<0.05$ were considered as a statistical significance for the meta-analysis.

What is more, the level of evidence for the outcomes was assessed using the framework in the Cochrane Handbook for Systematic Reviews of Interventions (22). A funnel plot was used to assess the risk of publication bias for outcomes that included at least 10 statistically significant studies.

\section{RESULTS}

Initially, a total of 1406 studies were identified by our search strategy. First, 478 records were excluded because of duplication. Second, 863 studies were excluded that were irrelevant to our inclusion criteria by screening records. Third, 39 records of the remaining 65 were excluded by reading the full text (13 included irrelevant patients, 8 without reporting outcomes, 9 reviewers, 7 without complete data, and 2 duplicate publication). Finally, the remaining 26 studies were included with 8095 patients in our meta-analysis (Figure 1).

The characteristics of the included studies are shown in Supplementary Table 1 . All the included studies -6 prospective studies (23-28) and 20 retrospective studies (22, 29-47)-were cohort observational studies with no randomization. There were 3292 and 4803 patients in the LPN and OPN groups, respectively. The mean ages ranged from 49.3 to 63.7 years and from 46.2 to 65 years in LPN and OPN, respectively. The mean MINORS scores of all the included studies were 11.9 (from 6 to 18). Twelve included studies $(22,27,29,31,33,36-38,40,42,43,46)$ were found to have a high risk of bias because of the selection of patients, performance bias, and observer bias of outcomes according to the ROBINS-I tool. The others had a moderate risk of bias (in Supplementary Table 2).

\section{Surgical Outcomes}

There was no statistical difference between LPN and OPN for operation time ( $\mathrm{p}=0.13$, MD: $11.15 \mathrm{~min}, 95 \% \mathrm{CI}:-3.27,25.57$, Figure 2A). Meanwhile, no clinically meaningful differences were found when $\mathrm{T} 1 \mathrm{a}(\mathrm{p}=0.11, \mathrm{MD}=20.06 \mathrm{~min}, 95 \% \mathrm{CI}:-4.75$, 44.87 , Figure 2B) was analyzed in subgroup analyses. The quality of evidence was low because of high heterogeneity and the potential of performance biases.

Less EBL was associated with the LPN group in the total analysis $(\mathrm{P}<0.00001, \mathrm{MD}$ : $-66.16 \mathrm{~mL}, 95 \% \mathrm{CI}:-74.56,-57.77$, Figure 2C) and subgroup analysis $(\mathrm{p}<0.0001, \mathrm{MD}:-51.79 \mathrm{~mL}$, 95\% CI: -74.88, -28.71, Figure 2D), respectively. Similarly, a

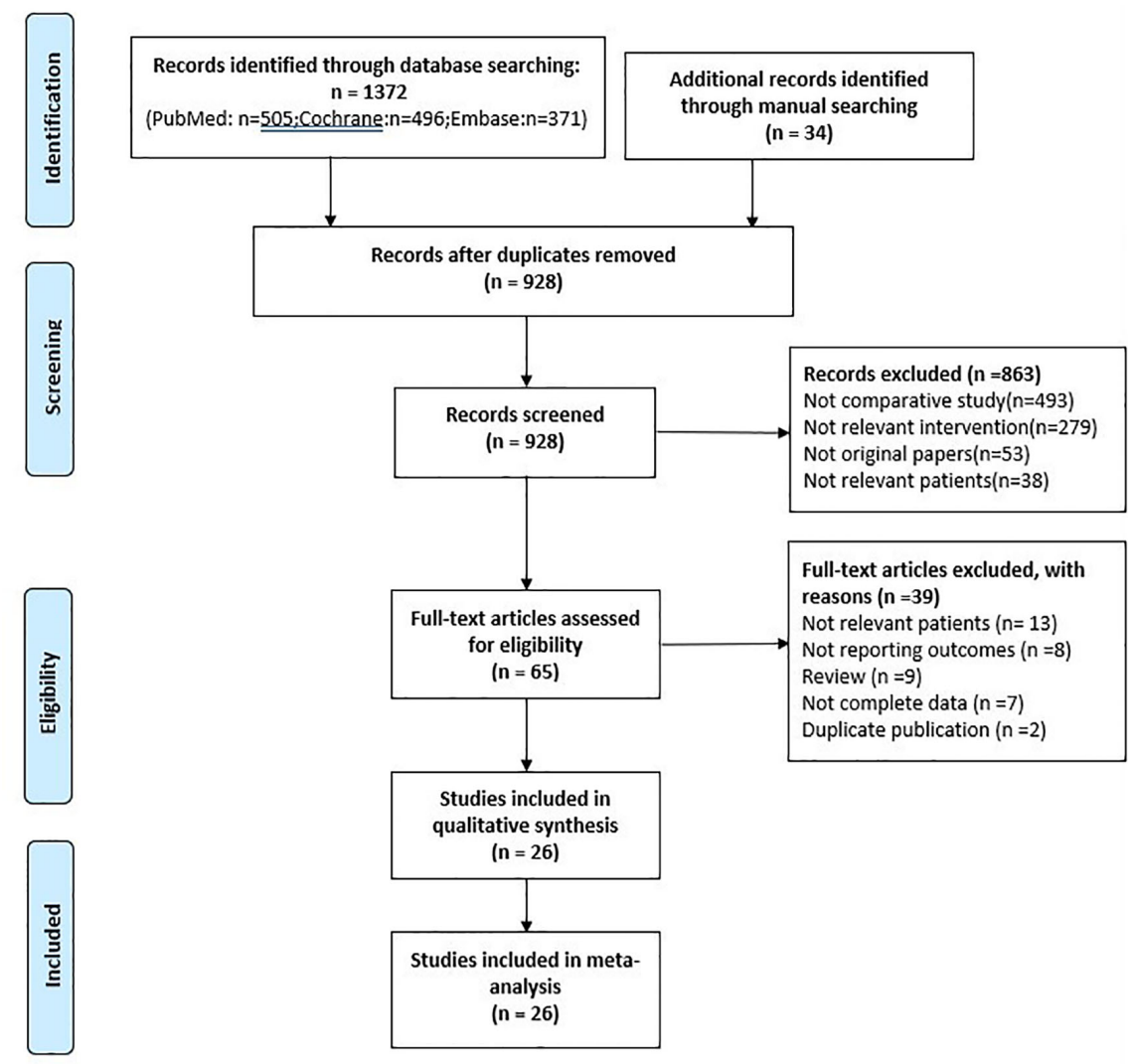

FIGURE 1 | PRISMA flow diagram. 


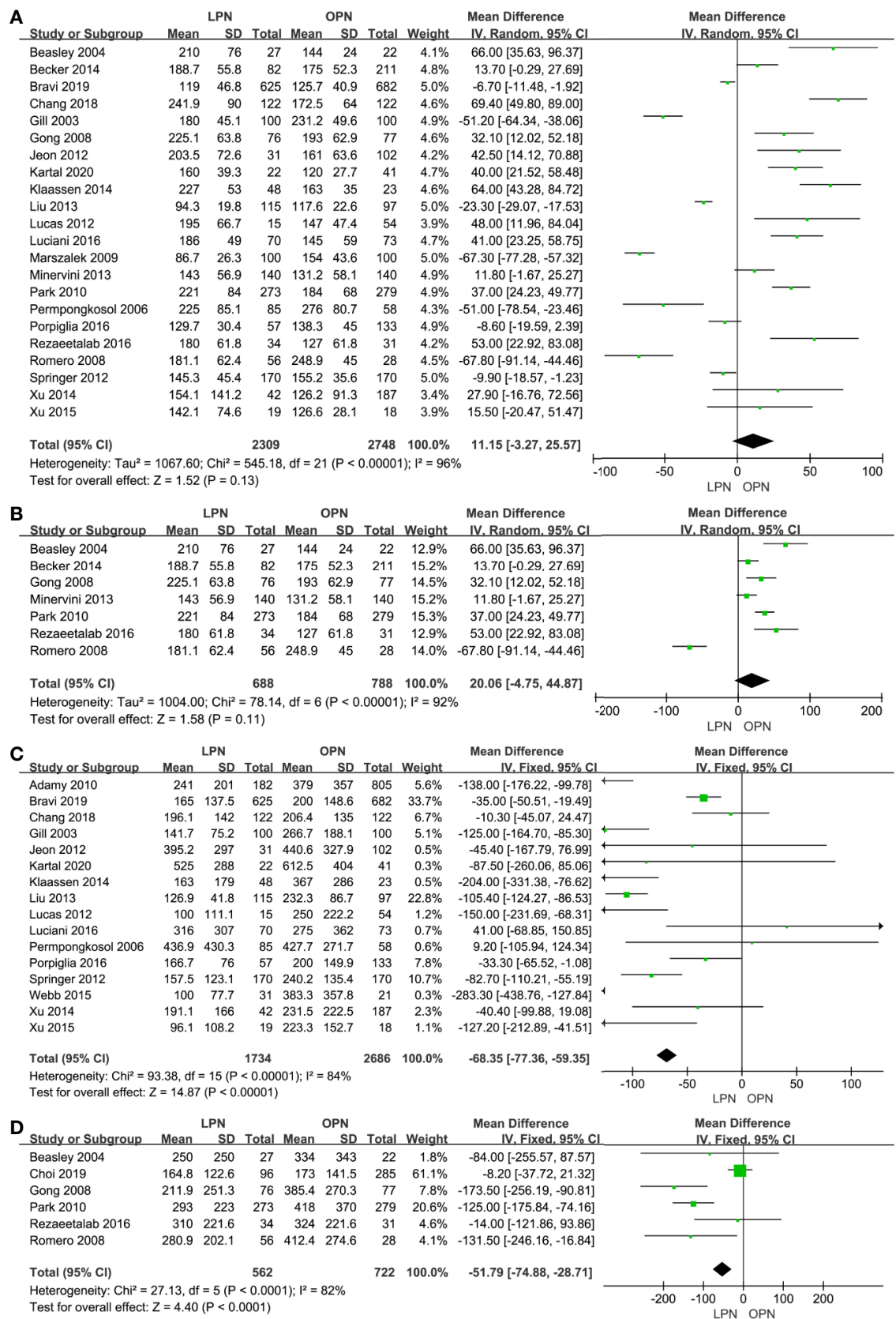

FIGURE 2 | Forest plot and meta-analysis of operation time (A) and EBL (C), the subgroup analysis of operation time (B) and EBL (D).

lower blood transfusion rate was found in the LPN group $(\mathrm{p}=0.04$, OR: $0.75,95 \%$ CI: 0.57-0.99, Figure 3A). The quality of evidence for EBL and transfusion both were moderate.

For LOS, there was a statistically significant difference between the two surgical techniques $(p<0.00001, M D:-2.01$ days, 95\% CI: $-2.58,-1.45$, Figure 3B). Moreover, subgroup analysis showed that a shorter LOS was related to LPN $(\mathrm{p}<0.00001, \mathrm{MD}:-2.03$ days, 95\% CI: $-2.43,-1.63$, Figure 3C) for the clinical stage of T1a. The quality of evidence was judged to be moderate according to the Cochrane Handbook.
No clinically meaningful differences were found between two groups for term of intraoperative complications $(\mathrm{p}=0.94$, OR: 1.01, 95\% CI: 0.69, 1.49, Figure 4B). However, fewer complications were found in terms of both total $(\mathrm{p}=0.03$, OR: $0.80,95 \%$ CI: $0.66,0.98$, Figure $4 \mathrm{~A}$ ) and postoperative complications ( $\mathrm{p}=0.02$, OR: $0.75,95 \% \mathrm{CI}: 0.59,0.96$, Figure 4C). The quality of evidence was graded as low because of no classification of complications and the potential of performance, detection, and attrition biases influencing the estimate of effect. 


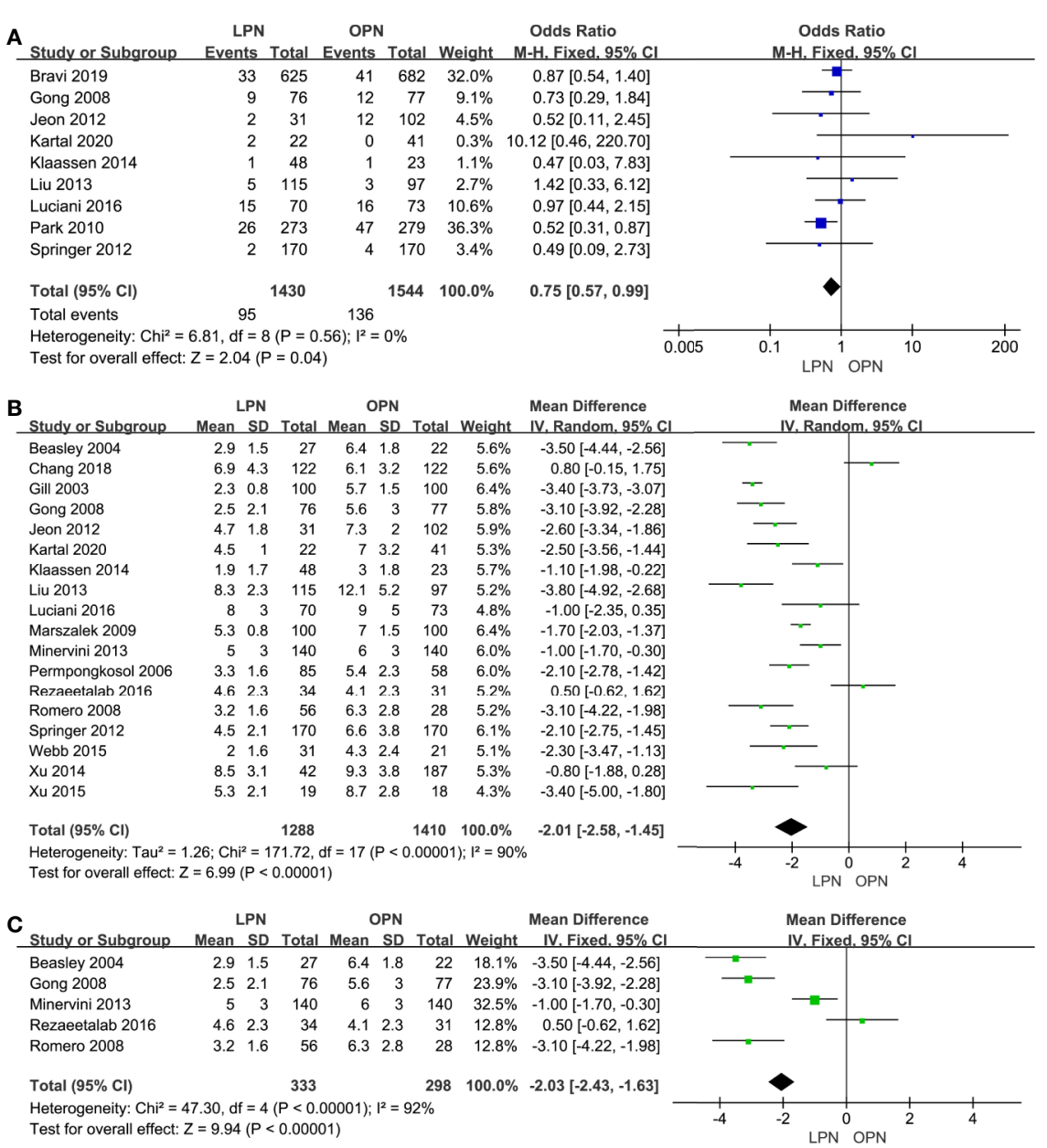

FIGURE 3 | Forest plot and meta-analysis of blood transfusion rate (A) and LOS (B), the subgroup analysis of LOS (C)

\section{Oncological Outcomes}

The higher PSM was in connection with the LPN ( $\mathrm{p}=0.005$, OR: 1.51, 95\% CI: 1.13, 2.01, Figure 5A). Nonetheless, no statistically significant difference was found in subgroup analysis $(p=0.23$, OR: 1.49 , 95\% CI: 0.78, 2.85, Figure 5B). The quality of evidence was judged to be low because of selection bias and inconsistency of results from populations.

There was no clinically meaningful differences for recurrence between the LPN and OPN (p=0.56, OR: 1.12, 95\% CI: 0.76, 1.67, Figure 5C). The quality of evidence was moderate.

For survival outcomes, there was a statistically significant difference between the two surgical techniques regarding OS $(\mathrm{p}<0.00001$, OR: $2.45,95 \%$ CI: 1.79, 3.37, Figure 5D). The quality of evidence was graded as very low because of the potential of selection bias and circumstantial evidence. Yet, no significant difference was found for terms of CSS ( $p=0.72$, HR: 1.13, 95\% CI: 0.58, 2.18, Figure 5E) and DFS ( $\mathrm{p}=0.72$, HR: 1.14 , 95\% CI: 0.56, 2.36, Figure 5F). The quality of evidence was low because of the small sample size, the potential of performance, and detection biases, respectively.

\section{Functional Outcomes}

No statistically significant difference between the two surgical techniques regarding eGFR ( $\mathrm{p}=0.31, \mathrm{MD}:-1.60 \mathrm{~mL} / \mathrm{min} / 1.73 \mathrm{~m}^{2}$, 95\% CI: $-4.71,1.51$, Figure 6A). There was a clinically meaningful difference between the two groups for term of $\mathrm{sCr}$ ( $\mathrm{p}=0.002$, MD: $-0.08 \mathrm{mg} / \mathrm{dL}, 95 \% \mathrm{CI}:-0.14,-0.03$, Figure 6B). The quality of evidence was low because of high heterogeneity and the potential of performance bias, respectively.

\section{Publication Bias}

We analyzed possible publication bias generating funnel plots used for the evaluated comparisons of outcomes. There was apparent publication bias in most of the outcomes. For example, we present the funnel plot of PSM showing the obvious asymmetry (Figure 7).

\section{DISCUSSION}

We believed that there is a different effect on surgical, oncological, and functional outcomes between LPN and OPN. 


\begin{tabular}{|c|c|c|c|c|c|c|}
\hline \multirow{2}{*}{ A } & \multicolumn{2}{|l|}{ LPN } & \multirow{2}{*}{$\begin{array}{l}\text { OPN } \\
\text { Events }\end{array}$} & \multirow{2}{*}{ Total } & \multirow{2}{*}{ Weight } & \multirow{2}{*}{$\begin{array}{l}\text { Odds Ratio } \\
\text { M-H, Fixed, 95\% C }\end{array}$} \\
\hline & Events & Total & & & & \\
\hline Beasley 2004 & 3 & 27 & 3 & 22 & $1.3 \%$ & $0.79[0.14,4.38]$ \\
\hline Bravi 2019 & 625 & 625 & 682 & 682 & & Not estimable \\
\hline Gill 2003 & 19 & 100 & 13 & 100 & $4.8 \%$ & $1.57[0.73,3.38]$ \\
\hline Gong 2008 & 17 & 76 & 30 & 77 & $10.6 \%$ & $0.45[0.22,0.92]$ \\
\hline Jeon 2012 & 4 & 31 & 16 & 102 & $3.0 \%$ & $0.80[0.25,2.59]$ \\
\hline Klaassen 2014 & 8 & 48 & 9 & 23 & $4.6 \%$ & $0.31[0.10,0.96]$ \\
\hline Liu 2013 & 16 & 115 & 10 & 97 & $4.3 \%$ & $1.41[0.61,3.26]$ \\
\hline Lucas 2012 & 1 & 15 & 11 & 54 & $2.0 \%$ & $0.28[0.03,2.36]$ \\
\hline Luciani 2016 & 32 & 70 & 29 & 73 & $7.0 \%$ & $1.28[0.66,2.48]$ \\
\hline Marszalek 2009 & 24 & 100 & 22 & 100 & $7.6 \%$ & $1.12[0.58,2.16]$ \\
\hline Minervini 2013 & 21 & 140 & 25 & 140 & $9.7 \%$ & $0.81[0.43,1.53]$ \\
\hline Park 2010 & 18 & 273 & 19 & 279 & $8.0 \%$ & $0.97[0.50,1.88]$ \\
\hline Permpongkosol 2006 & 6 & 85 & 15 & 58 & $7.6 \%$ & $0.22[0.08,0.60]$ \\
\hline Porpiglia 2016 & 10 & 57 & 32 & 133 & $7.2 \%$ & $0.67[0.30,1.48]$ \\
\hline Rezaeetalab 2016 & 12 & 34 & 11 & 31 & $3.4 \%$ & $0.99[0.36,2.74]$ \\
\hline Romero 2008 & 14 & 56 & 15 & 28 & $6.8 \%$ & $0.29[0.11,0.75]$ \\
\hline Springer 2012 & 7 & 170 & 10 & 170 & $4.4 \%$ & $0.69[0.26,1.85]$ \\
\hline Webb 2015 & 3 & 31 & 0 & 21 & $0.2 \%$ & $5.28[0.26,107.74]$ \\
\hline Xu 2014 & 15 & 42 & 68 & 187 & $7.3 \%$ & $0.97[0.48,1.95]$ \\
\hline Total $(95 \% \mathrm{Cl})$ & & 2095 & & 2377 & $100.0 \%$ & $0.80[0.66,0.98]$ \\
\hline Total events & 855 & & 1020 & & & \\
\hline Heterogeneity: Chi & $2, d f=$ & & & & & \\
\hline
\end{tabular}

Test for overall effect: $Z=2.18(P=0.03)$

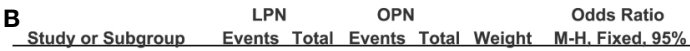

\begin{tabular}{lrrrrrr} 
Study or Subgroup & Events & Total & Events & Total Weight & M-H. Fixed, 95\% C \\
\hline Chang 2018 & 9 & 122 & 4 & 122 & $7.1 \%$ & $2.35[0.70,7.85]$
\end{tabular}

Gill 2003

Gong 2008

Klaassen 2014

Lucas 2012

Marszalek 2009

Minervini 2013

Park 2010

Permpongkosol 2006

Porpiglia 2016

Rezaeetalab 2016

Romero 2008

$\begin{array}{rrrr}4 & 122 & 7.1 \% & 2.35[0.70,7.85] \\ 0 & 100 & 0.9 \% & 11.58[0.63,212.19]\end{array}$

$\begin{array}{rrrr}0 & 100 & 0.9 \% & 11.58[0.63,212.19] \\ 4 & 77 & 7.0 \% & 1.56[0.42,5.78]\end{array}$

$\begin{array}{lll}4 & 77 & 7.0 \% \\ 2 & 23 & 6.4 \%\end{array}$

$\begin{array}{rrrrr}0 & 48 & 2 & 23 & 6.4 \% \\ 115 & 3 & 97 & 5.5 \%\end{array}$

\begin{tabular}{rrrrr}
13 & 115 & 3 & 97 & $5.5 \%$ \\
0 & 15 & 4 & 54 & $3.8 \%$ \\
\hline & 100 & 3 & 100 & $5.2 \%$
\end{tabular}

$\begin{array}{rrrrr}10 & 100 & 3 & 100 & 5.2 \%\end{array}$

$\begin{array}{lllll}1 & 140 & 7 & 140 & 13.3 \%\end{array}$

$\begin{array}{lllll}3 & 273 & 4 & 279 & 7.5 \%\end{array}$

$\begin{array}{rrr}4 & 279 & 7.5 \% \\ 2 & 58 & 4.4 \%\end{array}$

$\begin{array}{rrr}2 & 58 & 4.4 \% \\ 8 & 133 & 8.9 \%\end{array}$

85

57

$\begin{array}{ll}2 & 34 \\ 1 & 56\end{array}$

Total $(95 \% \mathrm{Cl})$

$1221 \quad 1242 \quad 100.0 \%$

Total events $55 \quad 55$

Heterogeneity: $\mathrm{Chi}^{2}=30.15, \mathrm{df}=12(\mathrm{P}=0.003) ;\left.\right|^{2}=60 \%$

Test for overall effect: $Z=0.07(P=0.94)$

$0.09[0.00,1.93]$

$3.99[1.10,14.45]$

$0.36[0.02,7.10]$

$0.14[0.02,1.13]$

$0.14[0.02,1.13]$

$0.76[0.17,3.45]$

$1.02[0.17,6.33]$

$0.57[0.12,2.76]$

$0.18[0.03,0.93]$

$1.01[0.69,1.49]$

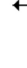
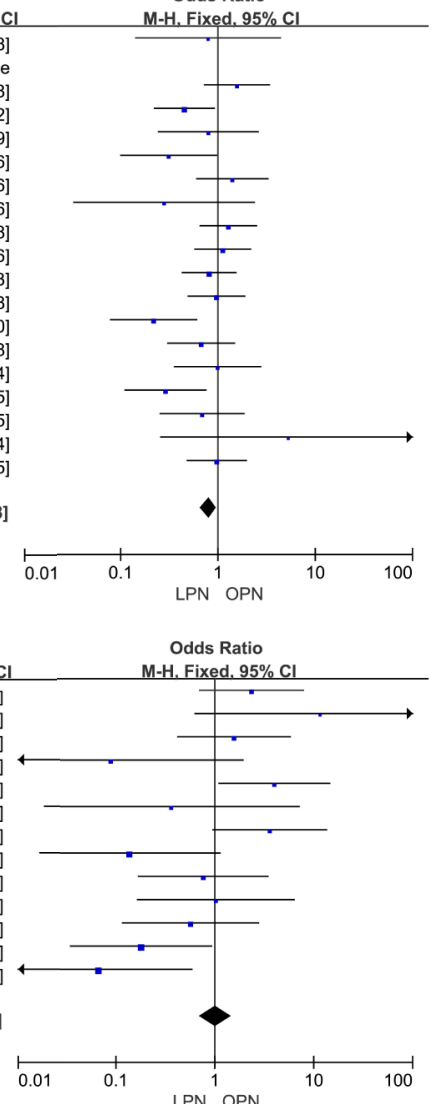

LPN

LPN OPN

OPN Odds Ratio

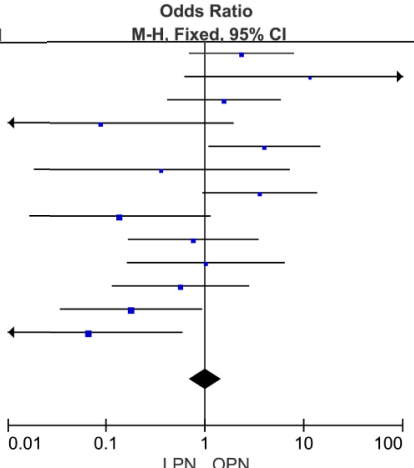

Odds Ratio

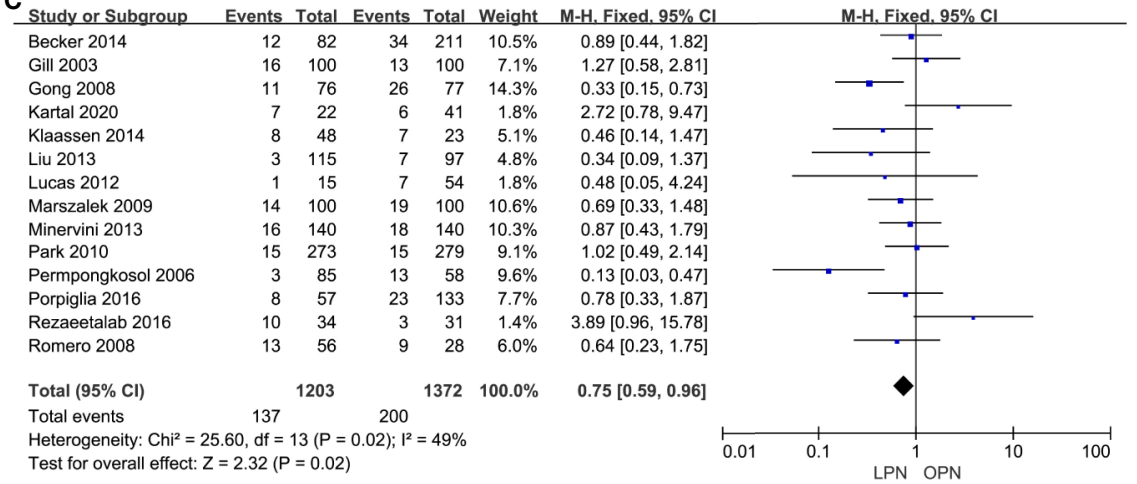

Test for overall effect: $Z=2.32(P=0.02)$ 


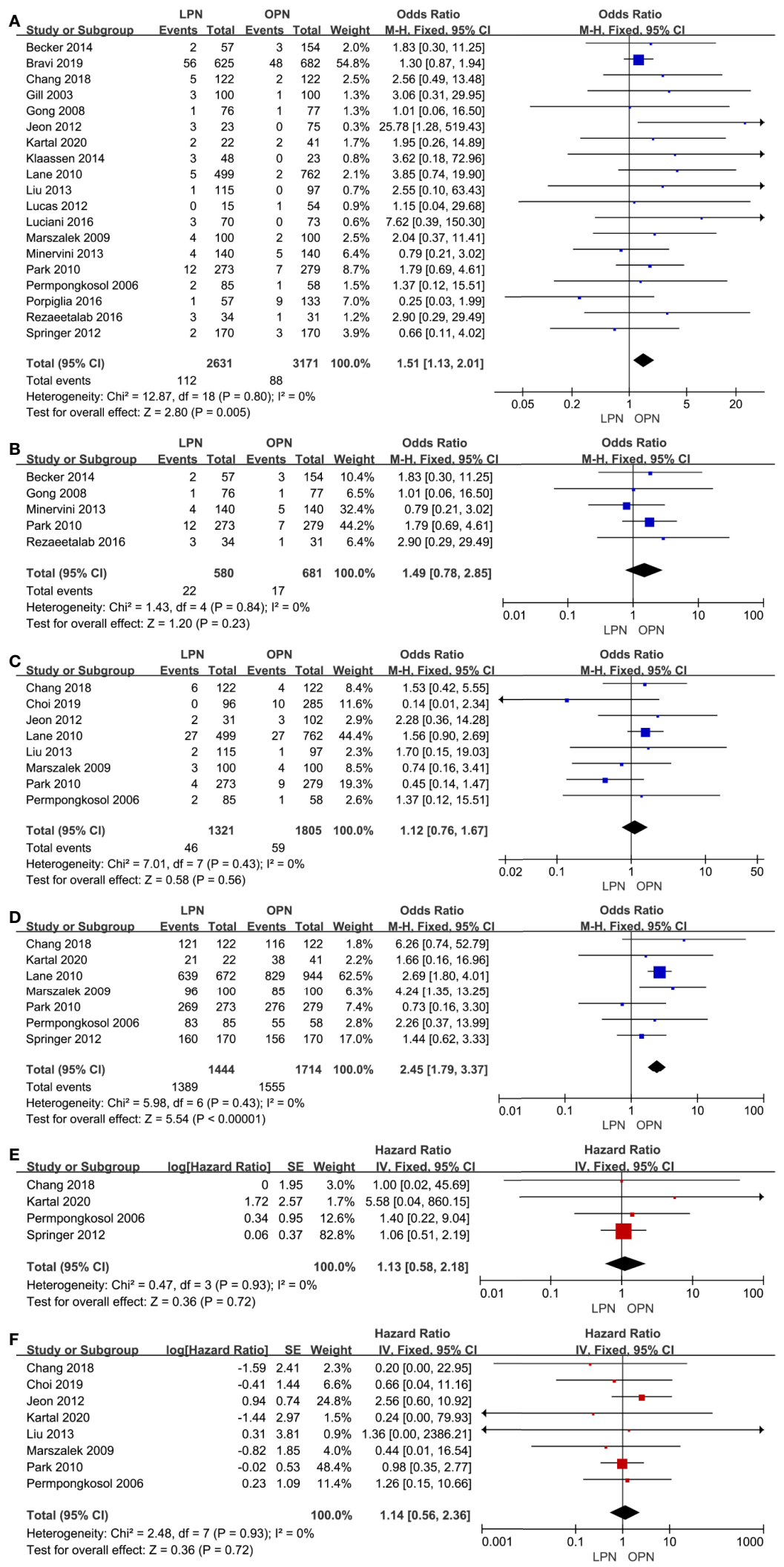

FIGURE 5 | Forest plot and meta-analysis of oncological outcomes: PSM (A), recurrence (C), OS (D), CSS (E), and DFS (F). The subgroup analysis of PSM (B). 


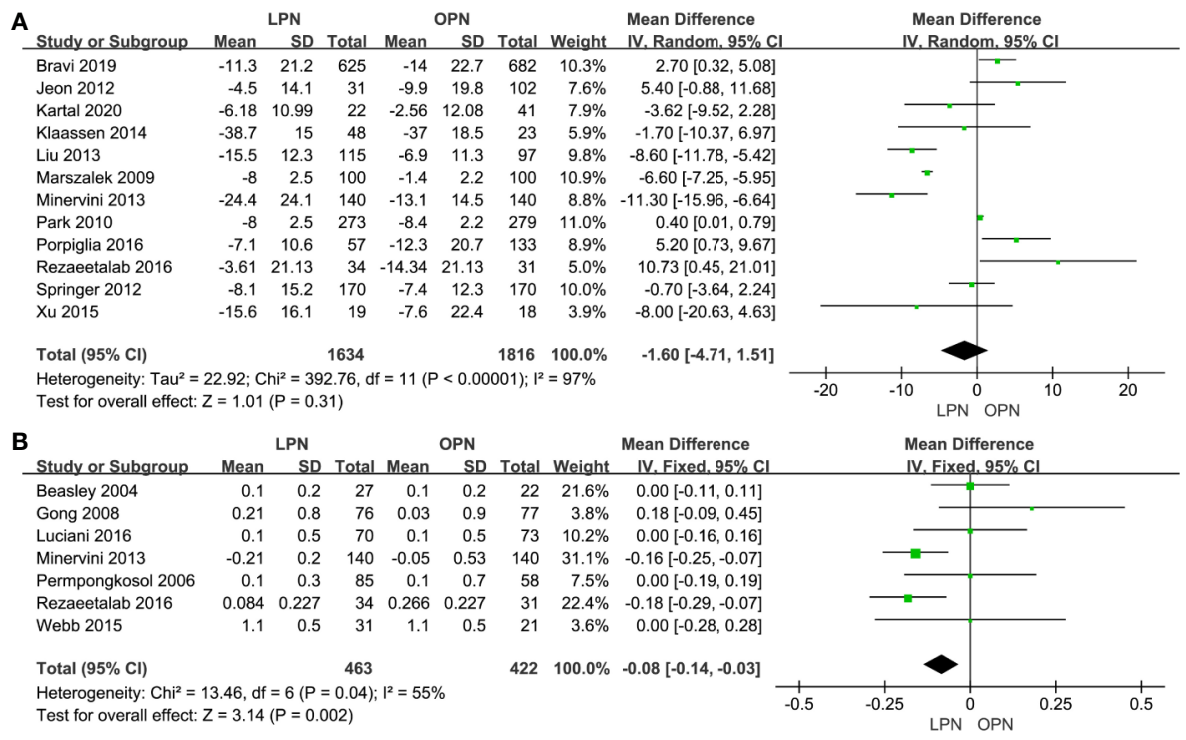

FIGURE 6 | Forest plot and meta-analysis of functional outcomes: eGFR (A) and sCr (B)

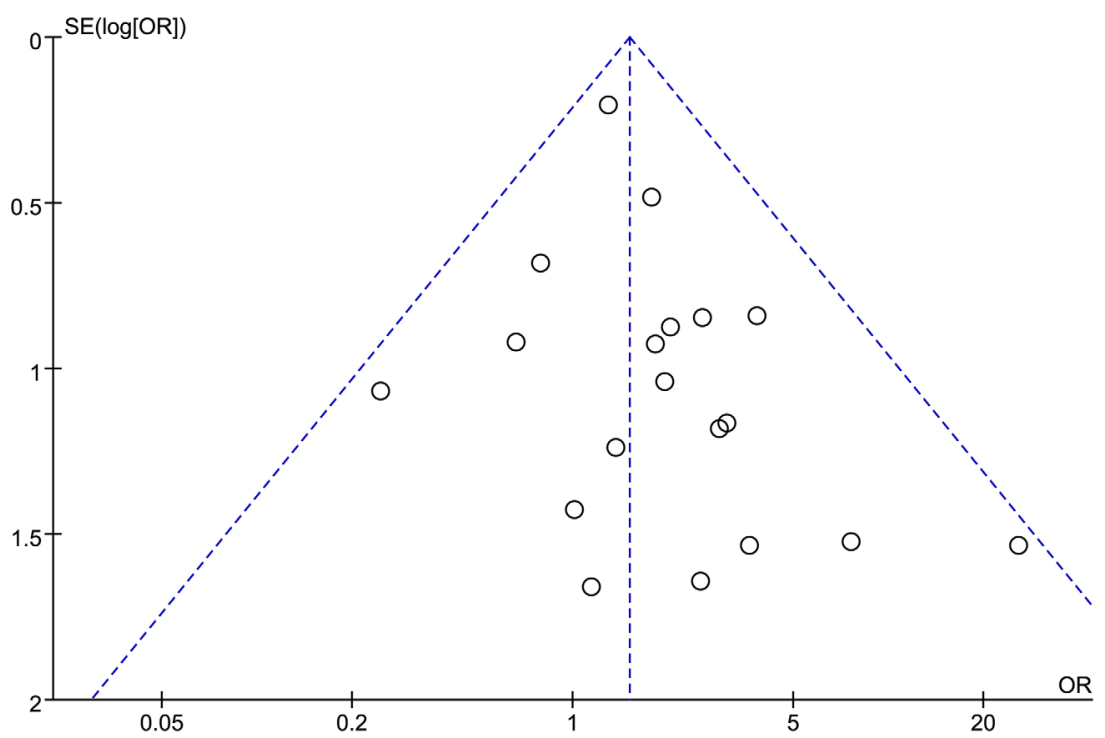

FIGURE 7 | Funnel plot of PSM.

vision that contribute to reduce blood loss providing precise dissection $(23,25,34)$. A lower transfusion rate is associated with postoperative survival in patients with renal cell carcinoma after nephrectomy and reduces potential risk factors, such as hemolysis in the clinic $(49,50)$. What is more, results of LOS are 2.01 days shorter for LPN than OPN with high heterogeneity because of lower complications, smaller wounds, and more rapid recovery $(23,34,44)$. We believe that the discharge criteria, postoperative care management, and characteristics of patients are associated with high heterogeneity. Due to the lack of scientific and strict classification of complications in most included studies and the lack of sufficient data, we only analyzed the complications classified into total, intraoperative, and postoperative complications according to the time of occurrence. Our cumulative analysis showed lower total and postoperative complications were related to the LPN compared with the OPN and showed no clinically meaningful differences were found for term of intraoperative complications. Marszalek et al. and Rezaeetalab et al. believe that shorter anesthesia and ischemia times are attributed to the lower perioperative 
complications, respectively $(25,28)$. On the other hand, some series thought the small difference in mean tumor size and tumor location were associated with fewer complications $(26,34,35$, 41). The fewer complications are beneficial to improve postoperative recovery and quality of life, which is more popular in the clinic.

Second, the analysis of oncological outcomes indicated that a higher PSM was found in the group of LPN. Subgroup analysis showed no significantly meaningful differences in term of PSM between two groups for T1a stage tumor. We believe that tumor size and learning curve play an important role in the discrepancy because the limited operation range of the laparoscope and less complete excision than open surgery was associated with high PSM for larger tumors. Current research suggests that a higher PSM is closely related to a higher incidence of local relapses, especially in large RCC, poorly differentiated, and/or more centrally located (51-53). However, the LPN and OPN accessed yield comparable in terms of recurrence, CSS, and DFS. It may be related to differences in pathological stage and follow-up time. In addition, we found that a high OS was associated with the LPN. Lane et al. thought that it had something to do with the renal functional outcomes (38). However, there is no clinical significance because of too many influences, such as underlying diseases and accidents.

Third, our results notably reveal that significant differences were found for postoperative change in $\mathrm{sCr}$ but not for postoperative changes in eGFR with moderate and high heterogeneity, respectively. The differences of patients' characteristics, ischemia technique, and time are associated with heterogeneity. Marszalek et al. believe that the functional outcomes were closely related to intraoperative renal perfusion, caused by either arterial clamping or capnoperitoneum or capnoretroperitoneum (25). In addition, Bravi et al. suggest that surgical manipulation and suture/hemostatic techniques may affect early postoperative renal function (23). In addition, ischemia technique and time are related to postoperative renal function $(26,28)$. Subgroup analysis was not possible due to the lack of data. Recently, a systematic review proved that functional outcomes had something to do with ischemia technique, but none of the available ischemia techniques could be recommended over the other (54). Yet, a $0.08 \mathrm{mg} / \mathrm{dL}$ less increased $\mathrm{sCr}$ has no significant difference in the clinic.

Few studies focused on quality of life after PN. Becker et al. report that LPN and OPN were equivalent with postoperative quality of life, which needs further argument (31). For cost, current studies suggested that LPN is more cost-effective than OPN because of shorter LOS (55).

\section{REFERENCES}

1. Ljungberg B, Albiges L, Bensalah K, Bex A, Giles RH, Hora M, et al. EAU Guidelines on Renal Cell Carcinoma 2020. In: European Association of Urology Guidelines 2020 Edition. presented at the EAU Annual Congress Amsterdam 2020. Arnhem, The Netherlands: European Association of Urology Guidelines Office (2020).

2. Campbell S, Uzzo RG, Allaf ME, Bass EB, Cadeddu JA, Chang A, et al. Renal Mass and Localized Renal Cancer: AUA Guideline. J Urol (2017) 198(3):5209. doi: 10.1016/j.juro.2017.04.100
Although we performed this meta-analysis with the rigorous methodology of review and quantitative synthesis, some inherent limitations cannot be avoided. First, there were no prospective randomized controlled studies, which reduced the quality of evidence. Second, results should be applied carefully in clinical practice because of great heterogeneity in terms of operative time, LOS, and variations of eGFR. Third, some data were unsuitable to evaluate oncologic outcomes, including recurrence, OS, CSS, and DFS, because of insufficient follow-up period. Finally, there was evidence of the apparent publication bias. Computer-based literature searching could not include all relevant studies. Gray literature also could not be included.

\section{CONCLUSIONS}

This meta-analysis revealed that the LPN is a feasible and safe alternative to the OPN with comparable surgical, oncologic, and functional outcomes. However, the results should be applied prudently in the clinic because of the low quality of evidence. Further quality studies are needed to evaluate effectiveness of LPN and its postoperative quality of life compared with OPN.

\section{DATA AVAILABILITY STATEMENT}

All datasets presented in this study are included in the article/ Supplementary Material.

\section{AUTHOR CONTRIBUTIONS}

Conceived and designed the experiments: AW. Analyzed the data: CY, YD, LP, and HW. Contributed reagents/materials/ analysis: YD, LP, TW, and XZ. Wrote the manuscript: CY and YD. All authors contributed to the article and approved the submitted version.

\section{SUPPLEMENTARY MATERIAL}

The Supplementary Material for this article can be found online at: https://www.frontiersin.org/articles/10.3389/fonc. 2020. 583979/full\#supplementary-material

SUPPLEMENTARY TABLE 1 | Characteristics and quality assessment of included studies.

3. Tae JH, Pyun JH, Shim JS, Cho S, Kang SG, Ko YH, et al. Oncological and functional outcomes of robot-assisted radical cystectomy in bladder cancer patients in a single tertiary center: Can these be preserved throughout the learning curve? Invest Clin Urol (2019) 60(6):463-71. doi: 10.4111/icu.2019.60.6.463

4. MacLennan S, Imamura M, Lapitan MC, Omar MI, Lam TB, HilvanoCabungcal AM, et al. Systematic review of perioperative and quality-of-life outcomes following surgical management of localised renal cancer. Eur Urol (2012) 62(6):1097-117. doi: 10.1016/j.eururo.2012.07.028

5. Van Poppel H, Da Pozzo L, Albrecht W, Matveev V, Bono A, Borkowski A, et al. A prospective, randomised EORTC intergroup phase 3 study comparing 
the oncologic outcome of elective nephron-sparing surgery and radical nephrectomy for low-stage renal cell carcinoma. Eur Urol (2011) 59 (4):543-52. doi: 10.1016/j.eururo.2010.12.013

6. Huang WC, Elkin EB, Levey AS, Jang TL, Russo P. Partial nephrectomy versus radical nephrectomy in patients with small renal tumors-is there a difference in mortality and cardiovascular outcomes? J Urol (2009) 181(1):5561; discussion -2. doi: 10.1016/j.juro.2008.09.017

7. Gill IS, Kavoussi LR, Lane BR, Blute ML, Babineau D, Colombo JRJr., et al. Comparison of 1,800 laparoscopic and open partial nephrectomies for single renal tumors. J Urol (2007) 178(1):41-6. doi: 10.1016/j.juro.2007.03.038

8. Pierorazio PM, Patel HD, Feng T, Yohannan J, Hyams ES, Allaf ME. Roboticassisted versus traditional laparoscopic partial nephrectomy: comparison of outcomes and evaluation of learning curve. Urology (2011) 78(4):813-9. doi: 10.1016/j.urology.2011.04.065

9. Feder MT, Patel MB, Melman A, Ghavamian R, Hoenig DM. Comparison of open and laparoscopic nephrectomy in obese and nonobese patients: outcomes stratified by body mass index. J Urol (2008) 180(1):79-83. doi: 10.1016/j.juro.2008.03.023

10. Ghani KR, Sukumar S, Sammon JD, Rogers CG, Trinh QD, Menon M. Practice patterns and outcomes of open and minimally invasive partial nephrectomy since the introduction of robotic partial nephrectomy: results from the nationwide inpatient sample. J Urol (2014) 191(4):907-12. doi: 10.1016/j.juro.2013.10.099

11. Reifsnyder JE, Ramasamy R, Ng CK, Dipietro J, Shin B, Shariat SF, et al. Laparoscopic and open partial nephrectomy: complication comparison using the Clavien system. JSLS (2012) 16(1):38-44. doi: 10.4293/108680812X 13291597716942

12. Choi JE, You JH, Kim DK, Rha KH, Lee SH. Comparison of perioperative outcomes between robotic and laparoscopic partial nephrectomy: a systematic review and meta-analysis. Eur Urol (2015) 67(5):891-901. doi: 10.1016/ j.eururo.2014.12.028

13. Patel MN, Bhandari M, Menon M, Rogers CG. Robotic-assisted partial nephrectomy. BJU Int (2009) 103(9):1296-311. doi: 10.1111/j.1464410X.2009.08584.x

14. Buttice S, Sener TE, Lucan VC, Lunelli L, Lagana AS, Vitale SG, et al. Hybrid Transvaginal NOTES Nephrectomy: Postoperative Sexual Outcomes. A Three-center Matched Study. Urology (2017) 99:131-5. doi: 10.1016/ j.urology.2016.09.023

15. Kallidonis P, Panagopoulos V, Kyriazis I, Vasilas M, Liatsikos E. Transvaginal specimen removal in minimally invasive surgery. World J Urol (2016) 34 (6):779-87. doi: 10.1007/s00345-016-1770-1

16. Zhao PT, Richstone L, Kavoussi LR. Laparoscopic partial nephrectomy. Int $J$ Surg (2016) 36(Pt C):548-53. doi: 10.1016/j.ijsu.2016.04.028

17. Shamseer L, Moher D, Clarke M, Ghersi D, Liberati A, Petticrew M, et al. Preferred reporting items for systematic review and meta-analysis protocols (PRISMA-P) 2015: elaboration and explanation. BMJ (2015) 350:g7647. doi: $10.1136 / \mathrm{bmj} . \mathrm{g} 7647$

18. Slim K, Nini E, Forestier D, Kwiatkowski F, Panis Y, Chipponi J. Methodological index for non-randomized studies (minors): development and validation of a new instrument. ANZ J Surg (2003) 73:712-6. doi: 10.1046/j.1445-2197.2003.02748.x

19. Brassetti A, Cacciamani G, Anceschi U, Ferriero M, Tuderti G, Miranda G, et al. Long-term oncologic outcomes of robot-assisted radical cystectomy (RARC) with totally intracorporeal urinary diversion (ICUD): a multicenter study. World J Urol (2019) 38(4):837-43. doi: 10.1007/s00345-01902842-3

20. Sterne JAC, Hernán MA, Reeves BC, Savović J, Berkman ND, Viswanathan M, et al. ROBINS-I: a tool for assessing risk of bias in non-randomised studies of interventions. Bmj (2016) 355:i4919. doi: 10.1136/bmj.i4919

21. Hozo SP, Djulbegovic B, Hozo I. Estimating the mean and variance from the median, range, and the size of a sample. BMC Med Res Methodol (2005) 5:13. doi: 10.1186/1471-2288-5-13

22. Klaassen Z, Kohut RM, Patel D, Terris MK, Madi R. A Single Surgeon's Experience with Open, Laparoscopic, and Robotic Partial Nephrectomy. Int Scholarly Res Notices (2014) 2014:1-5. doi: 10.1155/2014/430914

23. Bravi CA, Larcher A, Capitanio U, Mari A, Antonelli A, Artibani W, et al. Perioperative Outcomes of Open, Laparoscopic, and Robotic Partial Nephrectomy: A Prospective Multicenter Observational Study (The
RECORd 2 Project). Eur Urol Focus (2019) S2405-4569(19)30335-9. doi: 10.1016/j.euf.2019.10.013

24. Luciani LG, Chiodini S, Mattevi D, Cai T, Puglisi M, Mantovani W, et al. Roboticassisted partial nephrectomy provides better operative outcomes as compared to the laparoscopic and open approaches: results from a prospective cohort study. J Robot Surg (2017) 11(3):333-9. doi: 10.1007/s11701-016-0660-2

25. Marszalek M, Meixl H, Polajnar M, Rauchenwald M, Jeschke K, Madersbacher S. Laparoscopic and open partial nephrectomy: a matchedpair comparison of 200 patients. Eur Urol (2009) 55(5):1171-8. doi: 10.1016/ j.eururo.2009.01.042

26. Minervini A, Siena G, Antonelli A, Bianchi G, Bocciardi AM, Cosciani Cunico S, et al. Open versus laparoscopic partial nephrectomy for clinical T1a renal masses: a matched-pair comparison of 280 patients with TRIFECTA outcomes (RECORd Project). World J Urol (2014) 32(1):257-63. doi: 10.1007/s00345-0131155-7

27. Porpiglia F, Mari A, Bertolo R, Antonelli A, Bianchi G, Fidanza F, et al. Partial Nephrectomy in Clinical T1b Renal Tumors: Multicenter Comparative Study of Open, Laparoscopic and Robot-assisted Approach (the RECORd Project). Urology (2016) 89:45-51. doi: 10.1016/j.urology.2015.08.049

28. Rezaeetalab GH, Karami H, Dadkhah F, Simforoosh N, Shakhssalim N. Laparoscopic Versus Open Partial Nephrectomy for Stage Tla of Renal Tumors. Urol J (2016) 13(6):2903-7. doi: 10.22037/uj.v13i6.3572

29. Adamy A, Favaretto RL, Nogueira L, Savage C, Russo P, Coleman J, et al. Recovery of renal function after open and laparoscopic partial nephrectomy. Eur Urol (2010) 58(4):596-601. doi: 10.1016/j.eururo.2010.05.044

30. Beasley KA, Al Omar M, Shaikh A, Bochinski D, Khakhar A, Izawa JI, et al. Laparoscopic versus open partial nephrectomy. Urology (2004) 64(3):458-61. doi: 10.1016/j.urology.2004.04.028

31. Becker A, Pradel L, Kluth L, Schmid M, Eichelberg C, Ahyai S, et al. Laparoscopic versus open partial nephrectomy for clinical T1 renal masses: no impact of surgical approach on perioperative complications and long-term postoperative quality of life. World J Urol (2015) 33(3):421-6. doi: 10.1007/ s00345-014-1318-1

32. Chang KD, Abdel Raheem A, Kim KH, Oh CK, Park SY, Kim YS, et al. Functional and oncological outcomes of open, laparoscopic and robot-assisted partial nephrectomy: a multicentre comparative matched-pair analyses with a median of 5 years' follow-up. BJU Int (2018) 122(4):618-26. doi: 10.1111/bju.14250

33. Choi SY, Jung H, You D, Jeong IG, Song C, Hong B, et al. Robot-assisted partial nephrectomy is associated with early recovery of renal function: Comparison of open, laparoscopic, and robot-assisted partial nephrectomy using DTPA renal scintigraphy. J Surg Oncol (2019) 119(7):1016-23. doi: $10.1002 /$ jso. 25429

34. Gill IS, Matin SF, Desai MM, Kaouk JH, Steinberg A, Mascha E, et al. Comparative analysis of laparoscopic versus open partial nephrectomy for renal tumors in 200 patients. J Urol (2003) 170(1):64-8. doi: 10.1097/ 01.ju.0000072272.02322.ff

35. Gong EM, Orvieto MA, Zorn KC, Lucioni A, Steinberg GD, Shalhav AL. Comparison of Laparoscopic and Open Partial Nephrectomy in Clinical T1a Renal Tumors. J Endourol (2008) 22(5):953-8. doi: 10.1089/end.2007.0300

36. Jeon HG, Choi KH, Kim KH, Rha KH, Yang SC, Han WK. Comparison of Video-Assisted Minilaparotomy, Open, and Laparoscopic Partial Nephrectomy for Renal Masses. Yonsei Med J (2012) 53(1):151-7. doi: 10.3349/ymj.2012.53.1.151

37. Kartal I, Karakoyunlu N, Cakici C, Karabacak O, Sagnak L, Ersoy H. Oncological and functional outcomes of open versus laparoscopic partial nephrectomy in T1b tumors: A single-center analysis. Int Braz J Urol (2020) 46(3):341-50. doi: 10.1590/S1677-5538.IBJU.2018.0865

38. Lane BR, Gill IS. 7-year oncological outcomes after laparoscopic and open partial nephrectomy. J Urol (2010) 183(2):473-9. doi: 10.1016/j.juro.2009.10.023

39. Liu Z, Wang P, Xia D, Lou Y-F, Pan H-F, Wang S. Comparison between laparoscopic and open partial nephrectomy: Surgical, oncologic, and functional outcomes. Kaohsiung J Med Sci (2013) 29(11):624-8. doi: 10.1016/j.kjms.2013.01.021

40. Lucas SM, Mellon MJ, Erntsberger L, Sundaram CP. A comparison of robotic, laparoscopic and open partial nephrectomy. JSLS (2012) 16(4):581-7. doi: 10.4293/108680812X13462882737177

41. Park H, Byun SS, Kim HH, Lee SB, Kwon TG, Jeon SH, et al. Comparison of laparoscopic and open partial nephrectomies in tla renal cell carcinoma: a 
korean multicenter experience. Korean J Urol (2010) 51(7):467-71. doi: 10.4111/kju.2010.51.7.467

42. Permpongkosol S, Bagga HS, Romero FR, Sroka M, Jarrett TW, Kavoussi LR. Laparoscopic versus open partial nephrectomy for the treatment of pathological T1N0M0 renal cell carcinoma: a 5-year survival rate. J Urol (2006) 176(5):1984-8; discussion 8-9. doi: 10.1016/j.juro.2006.07.033

43. Romero FR, Rais-Bahrami S, Muntener M, Brito FA, Jarrett TW, Kavoussi LR. Laparoscopic partial nephrectomy in obese and non-obese patients: comparison with open surgery. Urology (2008) 71(5):806-9. doi: 10.1016/ j.urology.2007.11.047

44. Springer C, Hoda MR, Fajkovic H, Pini G, Mohammed N, Fornara P, et al. Laparoscopic vs open partial nephrectomy for T1 renal tumours: evaluation of long-term oncological and functional outcomes in 340 patients. BJU Int (2013) 111(2):281-8. doi: 10.1111/j.1464-410X.2012.11280.x

45. Webb CM, Kamel M, Eltahawy E, Faramawi MF, Shera AL, Davis R, et al. A comparative study of open, laparoscopic and robotic partial nephrectomy in obese patients. Urol Ann (2015) 7(2):231-4. doi: 10.4103/0974-7796.152023

46. Xu H, Ding Q, Jiang HW. Fewer complications after laparoscopic nephrectomy as compared to the open procedure with the modified Clavien classification system-a retrospective analysis from southern China. World J Surg Oncol (2014) 12:242. doi: 10.1186/1477-7819-12-242

47. Xu B, Wang JJ, Mi Y, Zhou LQ, Jin J, Zhang Q. Laparoscopic versus open partial nephrectomy for multilocular cystic renal cell carcinoma: a direct comparison based on single-center experience. Urol Int (2015) 94(1):83-7. doi: $10.1159 / 000363606$

48. Fu J, Ye S, Ye H-J. Retroperitoneal Versus Transperitoneal Laparoscopic Partial Nephrectomy: A Systematic Review and Meta-analysis. Chin Med Sci J (2015) 30(4):239-44. doi: 10.1016/s1001-9294(16)30007-4

49. Seon DY, Kwak C, Kim HH, Ku JH, Kim HS. Impact of perioperative blood transfusion on oncologic outcomes in patients with nonmetastatic renal cell carcinoma treated with curative nephrectomy: A retrospective analysis of a large, single-institutional cohort. Invest Clin Urol (2020) 61(2):136-45. doi: 10.4111/icu.2020.61.2.136
50. Delaney M, Wendel S, Bercovitz RS, Cid J, Cohn C, Dunbar NM, et al. Transfusion reactions: prevention, diagnosis, and treatment. Lancet (2016) 388(10061):2825-36. doi: 10.1016/s0140-6736(15)01313-6

51. Marchinena PG, Tirapegui S, Gonzalez IT, Jurado A, Gueglio G. Positive surgical margins are predictors of local recurrence in conservative kidney surgery for pT1 tumors. Int Braz J Urol (2018) 44(3):475-82. doi: 10.1590/ S1677-5538.IBJU.2017.0039

52. Tellini R, Antonelli A, Tardanico R, Fisogni S, Veccia A, Furlan MC, et al. Positive Surgical Margins Predict Progression-free Survival After Nephronsparing Surgery for Renal Cell Carcinoma: Results From a Single Center Cohort of 459 Cases With a Minimum Follow-up of 5 Years. Clin Genitourin Cancer (2019) 17(1):e26-31. doi: 10.1016/j.clgc.2018.08.004

53. Steinestel J, Steffens S, Steinestel K, Schrader AJ. Positive surgical margins in nephron-sparing surgery: risk factors and therapeutic consequences. World $J$ Surg Oncol (2014) 12:252. doi: 10.1186/1477-7819-12-252

54. Greco F, Autorino R, Altieri V, Campbell S, Ficarra V, Gill I, et al. Ischemia Techniques in Nephron-sparing Surgery: A Systematic Review and MetaAnalysis of Surgical, Oncological, and Functional Outcomes. Eur Urol (2019) 75(3):477-91. doi: 10.1016/j.eururo.2018.10.005

55. Mir SA, Cadeddu JA, Sleeper JP, Lotan Y. Cost comparison of robotic laparoscopic, and open partial nephrectomy. J Endourol (2011) 25(3):44753. doi: 10.1089/end.2010.0510

Conflict of Interest: The authors declare that the research was conducted in the absence of any commercial or financial relationships that could be construed as a potential conflict of interest.

Copyright (c) 2020 You, Du, Wang, Peng, Wei, Zhang, Li and Wang. This is an openaccess article distributed under the terms of the Creative Commons Attribution License (CC BY). The use, distribution or reproduction in other forums is permitted, provided the original author(s) and the copyright owner(s) are credited and that the original publication in this journal is cited, in accordance with accepted academic practice. No use, distribution or reproduction is permitted which does not comply with these terms. 